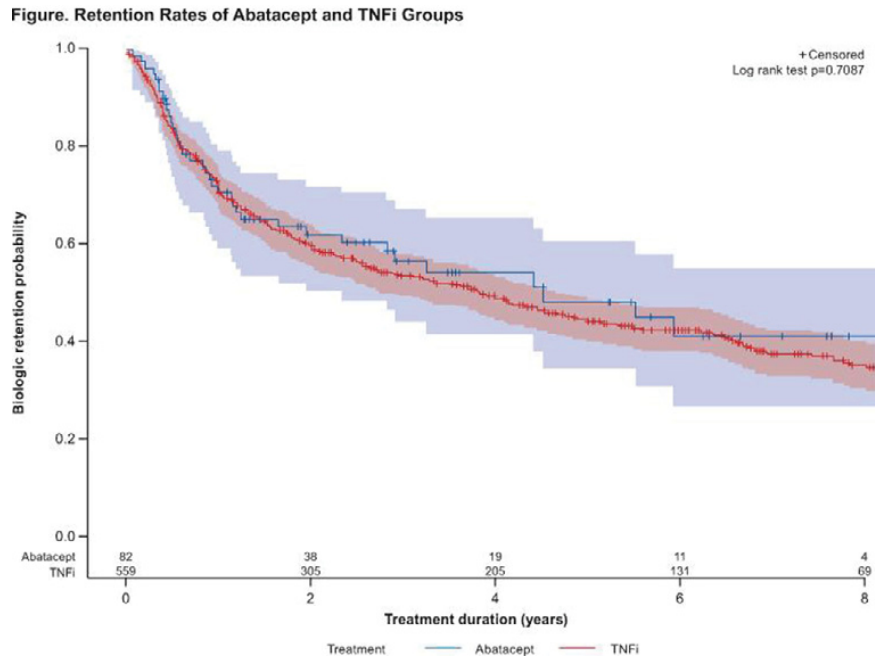

References:

[1] Schiff M, et al. Ann Rheum Dis 2014;73:86-94.

[2] Schiff M, et al. Ann Rheum Dis 2008;67:1096-1103.

Disclosure of Interest: D. Choquette Consultant for: BMS, Speakers bureau: BMS, L. Bessette Grant/research support from: Amgen, BMS, Janssen, Roche, UCB, AbbVie, Pfizer, Merck, Celgene, Sanofi, Lilly, Novartis, Consultant for: BMS, Janssen, Roche, UCB, AbbVie, Pfizer, Celgene, Lilly, Novartis, E. Alemao Shareholder of: BMS, Employee of: BMS, B. Haraoui Grant/research support from: BMS, Janssen, Roche, Consultant for: Abbvie, Amgen, BMS, Celgene, Janssen, Merck, Pfizer, Roche, Sandoz, UCB, Speakers bureau: Pfizer, UCB, F. Massicotte: None declared, M. Mtibaa Shareholder of: BMS, Employee of: BMS, E. Muratti Employee of: BMS, J.-P. Pelletier: None declared, R. Postema Shareholder of: BMS, Employee of: BMS, J.-P. Raynauld Speakers bureau: AbbVie, Amgen, BMS, Janssen, Pfizer, Roche, Sanofi, Novartis, UCB, M.-A. Rémillard: None declared, D. Sauvageau: None declared, A. Turcotte Consultant for: Amgen, Abbvie, BMS, Celegene, Janssen, Roche, Pfizer, Lilly, Novartis, Merck, Sanofi, UCB, Speakers bureau: Amgen, Abbvie, BMS, Celegene, Janssen, Roche, Pfizer, Lilly, Novartis, Merck, E. Villeneuve Consultant for: Celgene, Cimzia, Pfizer, Speakers bureau: Abbvie, Roche, BMS, L. Coupal: None declared

DOI: 10.1136/annrheumdis-2017-eular.2326

\section{FRI0231 THE FIRST REPORT OF SIGNIFICANT INCREASE OF BODY MASS INDEX IN RHEUMATOID ARTHRITIS PATIENTS TREATED WITH TOFACITINIB DURING 12-MONTH FOLLOW-UP}

D. Novikova, I. Kirillova, E. Luchikhina, E. Markelova, H. Udachkina,

N. Demidova, A. Misiyuk, T. Popkova, A. Volkov, L. Denisov, D. Karateev.

V.A.Nasonova Research Institute of Rheumatology, Moscow, Russian Federation

Objectives: to evaluate the effects of tofacitinib (TOFA) on cardiovascular risk factors (CVRF) in rheumatoid arthritis (RA) patients (pts).

Methods: After 12-m follow-up the CVRF dynamic was assessed in 28 RA pts treated with TOFA (22 women, median age 54 [40;62] years, disease duration $39.5[16.5 ; 60.0] \mathrm{m}$, moderate to high activity (DAS28 - $5.1[4.6 ; 6.0]$, SDAI $26[21 ; 34])$, positive for ACCP $(75 \%) / R F(79 \%)$, who were non-responders to MTX at least $15 \mathrm{mg} /$ week and/or other synthetic DMARDs and biologic DMARDs. TOFA therapy was started in all pts with dose $5 \mathrm{mg}$ BID per os followed by the dose escalation to $10 \mathrm{mg}$ BID in $8(29 \%)$ pts. TOFA used in combination with MTX in 27 (96\%) pts, leflunomide in 1 (4\%). Low-dose oral corticosteroids (<10 $\mathrm{mg} /$ day prednisone or equivalent) were received by $9(35 \%)$ pts. Remission or low disease activity was achieved in 55\% pts (DAS28), 77\% (SDAI). At baseline the most of pts had multiple CVRF and subclinical organ damage. Cardioprotective therapy received $16(57 \%)$ pts (beta-blockers - 7, angiotensin II receptor type $2 /$ ACE inhibitors - 11, statins - 11, dihydropyridine calcium channel blockers 7).

Results: The incidence rate of arterial hypertension (67\% vs $70 \%$ ), overweight (57\% vs $72 \%$ ), abdominal obesity $(61 \%$ vs $68 \%)$, physical inactivity (64\% vs $47 \%)$, smokers/ex-smokers (25\%/21\% vs $21 \% / 25 \%)$, menopausal status ( $59 \%$ vs $59 \%$ ), DM type 2 ( $7 \%$ vs $7 \%$ ), mSCORE $\geq 5 \%$ ( $21 \%$ vs $28 \%$ ), subclinical carotid atherosclerosis $(64 \%$ vs $64 \%)$, cardiac heart failure with preserved ejection fraction $(7 \%$ vs $7 \%$ ) did not change significantly. Blood pressure remained stable over time except 1 pt. An increase in body mass index (BMI) was observed from $26.2[22.9 ; 28.9]$ to $26.7[24.0 ; 30.1], \mathrm{p}<0.001$, waist circumference from $86[76 ; 97]$ to 91 [80; 103], $\mathrm{p}=0,001$. The increase of $\mathrm{BMl}<5 \%$ was observed in $11(39 \%)$ pts, $5 \%-10 \%-7(25 \%),>10 \%-6(21 \%)$. The normal BMI remained in $7(25 \%)$ pts, overweight $-9(32 \%)$, obese class I - $3(11 \%)$, the rest of pts passed to a higher category of BMI (from normal BMI to overweight $-4(14 \%)$, from overweight to obese class I - $1(4 \%)$, from obese class I to obese class II $-1(4 \%))$ and only 1 pt went from underweight to normal BMI (4\%). The change in BMI correlated negatively with DAS 28, SDAl at baseline $(r=-0.6, p<0.001)$.
BMI dynamic was independent of TOFA dose, achieving RA activity, dynamic of DAS 28, SDAI, use of cardioprotective therapy. Dynamic of lipid levels depended on statins treatment. An increase in HDL-C level from $1.35[0.88 ; 1.91]$ to 1.90 $[1.64 ; 2.17], \mathrm{p}<0.05$, a decrease in LDL-C level from $3.75[3.11 ; 4.40]$ to 2.60 [2.55; 2.93], $p<0.03$ was observed in pts treated with statins $(n=11)$. An increase in total cholesterol level from $4.60[4.14 ; 6.41]$ to 5.45 [4.56; 6.64], $p=0,001$ was observed in pts who didn't receive statins $(n=17)$. The change in HDL-C level correlated negatively with dynamic of DAS 28 , SDAI $(r=-0.4, p<0.05)$.

Conclusions: TOFA therapy of RA pts contributes to dramatical increase of BMI. Greater BMI dynamic associated with higher disease activity at baseline. BMI dynamic was independent of achieving RA activity and dynamic of DAS 28, SDAI. Co-administration TOFA and statins resulted in significant favorable changes of LDL-and HDL-cholesterol levels.

Disclosure of Interest: None declared

DOI: 10.1136/annrheumdis-2017-eular.2968

\section{FRI0232 TREATMENT EFFECTS OF ABATACEPT AND ANTI-TNF IN PATIENTS WITH RA WITH POOR PROGNOSTIC FACTORS: DATA FROM COMMUNITY RHEUMATOLOGY CLINICS}

E. Alemao ${ }^{1}$, K. Knapp ${ }^{2}$, V. Anupindi ${ }^{3}$, S. Annamalai ${ }^{4}$, G. Craig ${ }^{5} .{ }^{1}$ Bristol-Myers Squibb, Princeton; ${ }^{2}$ Discus Analytics, Spokane; ${ }^{3} \mathrm{Mu}$ Sigma, Princeton, United States; ${ }^{4}$ Mu Sigma, Bangalore, India; ${ }^{5}$ Arthritis Northwest, Spokane, United States

Background: Poor prognostic factors (PPFs; e.g. elevated anti-citrullinated protein antibody/RF levels and erosions) are associated with higher disability and mortality in RA. ${ }^{1-2}$ In addition, high seropositivity or CRP/ESR levels are correlated with erosive disease. ${ }^{3}$

Objectives: To evaluate if the presence of specific PPFs of seropositivity with erosions $(P P F+)$ in patients (pts) with RA have an effect on treatment with abatacept (ABA) and anti-TNFs.

Methods: This retrospective study was based on electronic medical record data. This database includes $>6500$ pts with RA from 50 + rheumatologists. At each visit, data on diagnosis, medications and test results were collected. A homunculus was used to record joint tenderness, swelling, deformity or decreased range of motion. Disease activity was measured by DAS28 (ESR/CRP), SDAI, CDAI, RAPID3 and Vectra DA blood tests. For this analysis, pts aged $>18$ yrs with an RA diagnosis from 1 Jan 2009 to 3 Mar 2016 were followed until lost to follow-up, death or end of study period. Date of first ABA/anti-TNF prescription was designated as index date, preceded by the baseline $(B L)$ period. The $A B A$ cohort comprised pts with a record of $A B A$ in the study period, while the anti-TNF cohort comprised pts with a record of anti-TNF and no record of ABA in the study period. Primary outcome was change $(\Delta)$ in CDAl at 6 months $(\mathrm{M})$; other outcomes were SDAI, DAS28 (CRP), pain, RAPID3 and Patient Global Assessment. Descriptive statistics were used for $\mathrm{BL}$ characteristics. Univariate and multivariate regression analyses were

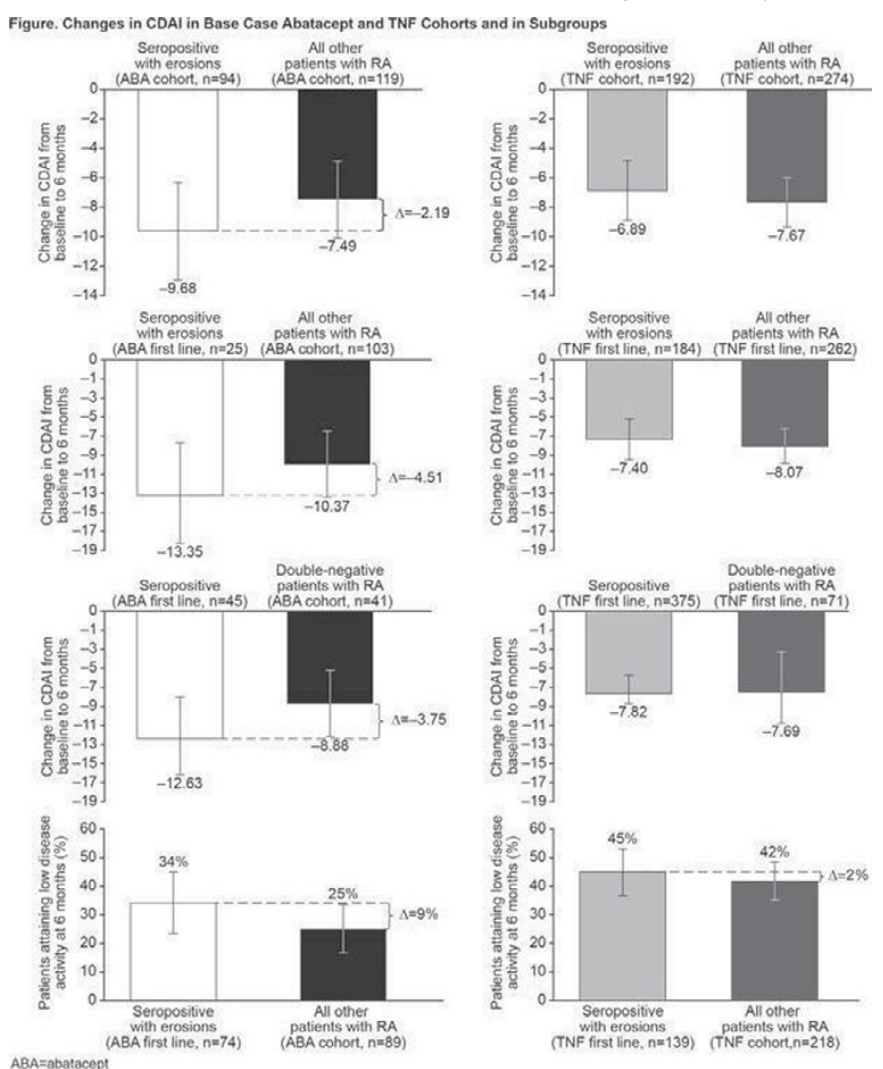

